\title{
Is There a Kuznets Curve in China's Rural Area?-An Empirical Analysis on Provincial Panel Data
}

\author{
Jian Zhan \\ School of Economics, Jinan University, Guangzhou, China \\ Email:zhj390617826@163.com
}

Received 10 March 2016; accepted 16 April 2016; published 19 April 2016

Copyright (C) 2016 by author and Scientific Research Publishing Inc.

This work is licensed under the Creative Commons Attribution International License (CC BY). http://creativecommons.org/licenses/by/4.0/ c) (i) Open Access

\begin{abstract}
The academia always argue about whether there is a Kuznets curve for a long time, however, rare people care about Kuznets curve in countryside. The thesis first analyzes the possibility of the Kuznets curve in China' rural area theoretically; and then based on the provincial panel data, the thesis adopts fixed effect and random effect models to analyze the relationship between China's rural economic growth and income distribution inequality among rural residents, so as to verify whether the Kuznets curve is applicable in the rural area of our country. The results show that there is a Kuznets curve in the process of rural economic development in China, namely there is a reversed U-shaped relationship between rural economic growth and income inequality within rural residents. At the same time, the economic growth of most provinces has not yet reached the inflection point to reduce the income inequality degree.
\end{abstract}

\section{Keywords}

\section{Economic Development, Rural Income Distribution, Kuznets Curve}

\section{Introduction}

With over 30 years of reform and opening up, China's economic development and urbanization construction made remarkable achievements, especially its GDP, which has created a Chinese development miracle with an average annual growth rate of nearly $10 \%$. Nevertheless, in the meanwhile, the rapid economic development goes with the increasingly larger income gap among residents of our society. Urban and rural residents' income gap and regional income disparity have always been the focus of attention, while the internal rural residents' income gap has been ignored. According to Report on Chinese Economic Conditions in Rural Areas released by 
Huazhong Normal University in September 2012, Gene coefficient in rural areas reached 0.395 in 2011, which was very close to the international warning line 0.4. According to the National Bureau of Statistics (NBS) figures in 2014, the top $20 \%$ of high income rural residents is 8.24 times of the last $20 \%$ of low income group. With the rapid development of rural economy, rural residents' income gap is increasingly expanding at the same time, which affects social stability in rural areas. Therefore, correct understanding and handling of the contradiction between rural economy development and income distribution influences not only the overall situation of reform and development in rural areas, but also the possibility to realize a new socialist countryside goal.

\section{Literature Review}

A deeper study of economic development and income distribution can be traced back to the inverted U-shaped curve hypothesis put forward by Kuznets. With economic growth and income gap data analysis of 18 countries, such as Britain, the United States and Germany, Kuznets (1955) claimed that there is an inverted U-shaped curve phenomenon between economic growth and income distribution in the transformation process from traditional agricultural economy to a modern industrial economy. That is, income distribution shows a "first expanding, then shrinking" trend in the process of economic development, which forms an inverted "U" shaped curve that first rising and then falling in graph [1].

The controversy over this theory has never stopped for more than half a century, and mutinous scholars analyzed Kuznets's inverted U-shaped curve theoretically and empirically. Based on dual economic theory, Robinson established the mathematical model of the two departments to demonstrate that there is bound to occur a "first expanding, then shrinking" inverted U-shaped curve in the process of economic growth, which verifies Kuznets's hypothesis [2]. H. Chenery and M. Syrquin utilized development data of 53 countries to verify the ubiquity of inverted U-shaped phenomenon in the process of economic growth in developing countries [3]. Some scholars showed doubts toward Kuznets's hypothesis. For example, with the study of economic development of "four Asian Tigers" in twentieth Century, Felts (G. S. Fields) found that while there was rapid economic development, their income distribution has been greatly improved [4] [5]. Studies of Ranis and FeiJinghan and others also found that Taiwan (China) is decreasing in income inequality degree while having rapid economic growth. Deininger and Squire (1998) adopted panel data analysis to show that for over $80 \%$ countries, the inverted U-shaped relationship between residents' income level and distribution is not obvious statistically [6]. In fact, Kuznets himself also believed that the inverted U-shaped relationship between economic development and income distribution is conditional, which is influenced by economic, social, institutional and demographic factors.

As for whether there exists Kuznets curve in the process of China's economic development, domestic scholars is divided. According to our special national condition of the implementation of public ownership reform in the process of economic development, Chen Zongsheng (2002) put forward the Chen inverted U-shaped curve hypothesis that is "dual transition" in system reform and changing development pattern, and he also proved that income gap presents ladder form rise in the first half of the inverted U-shaped curve with national per capita income and the Gini coefficient data from 1981 to 1999 [7]. Nevertheless, after Zhao Renwei and Li Shi analyzed the cross-section data of internal income gap between urban and rural areas in various provinces, they argued that there is no Kuznets curve in China's economic development [8] [9]. However, taking people's living level index as development level index, Guo Xibao (2002) demonstrated that Kuznets curve also exists in China and that the expanding income inequality is a must for the economic development and transformation of low-income developing country from the perspective of development economics [10]. With an empirical analysis on provincial facial data, Liu Rongtian and Ye Mingqiang (2006) claimed that there exists inverted U-shaped relationship between China's economic growth and urban rural residents income difference. Although they discussed eastern, central and western areas respectively, the result is still significant [11]. Ma Xiaopeng and Gao Wei (2013) also showed the existence of Kuznets curve phenomenon in China, but argued that economic development has not yet reached in narrowing the inflection point of income distribution [12]. Lv Fei (2014) verified the relationship between economic development level and the overall income gap since reform and opening up, the results showed that there did exist the inverted U-shaped relationship between them [13].

In conclusion, it is easy to find that the inverted U-shaped relationship between economic development and income gap in urban and rural residents and between economic development and the overall income gap has always been an important topic in academic circle. Nevertheless, there is little concern for the existence of in- 
verted U-shaped relationship between economic development in China's rural areas and rural residents' internal income gap. In the process of China's urbanization, there is a big difference between urban and rural development regardless of economic development speed or social structure change. Therefore, it is of immediate significance to discuss whether there is rural Kuznets curve phenomenon during the process of economic development in China's rural areas. In the following part, the thesis will first analyzes the possibility of the Kuznets curve in China's rural area theoretically, and then conduct empirical analysis of the existence of Kuznets curve in rural China based on the panel data of 18 provinces from 1999 to 2013.

\section{Analysis of the Relationship between Economic Development in Rural China and Rural Residents' Income Gap}

\subsection{Theoretical Analysis of Economic Development in Rural China and Rural Residents' Income Distribution Gap}

Since the reform and opening up, China's rural residents' income increased significantly, while rural residents' income gap is enlarging. The inner relation of the two is more than complicated.

1) Analysis based on Lewis's dual economic theory

China's reform started from rural areas. Start with the previous collective "eating from the same big pot" transforming into the household contract responsibility system, rural population gradually liberated from agricultural production and rural surplus labor force constantly transfers to the urban non-agricultural sector in a large scale. Since the second and third industry labor productivity is far higher than that of agricultural sector, non-agricultural income enable a considerable part of rural residents that transfers first to have their income improve, which leads to the expansion of the rural residents' inner income gap. Numerous studies show that nonfarm activities and income is the main reason for the expanding income gap in rural China since the reform and opening up [14].

According to Lewis's dual economic theory, economic sectors can be divided into traditional agricultural sector and modern industrial sector. Therefore, the rural population can also be divided into non-agricultural population and agricultural population. There are first a handful of rural labor force with certain skills and human capital come to work in urban modern industrial sector in the early stage of economic development, which resulted in the expanding rural income gap. With rural people rush into city constantly later, non-agricultural population in rural areas increased, while agricultural population decreased, which led to an increasing agriculture resources per capita and a relatively scarce labor force. In the meanwhile, the per capita arable land enabled the promotion and application of modern agriculture and the increasing agricultural labor remuneration, which narrowed the income gap between agriculture sector and modern industrial sector, which in turn led to the income gap between non-agricultural population and agricultural population. On the other hand, some non-agricultural rural population with high income eventually turned into urban population in the process of population transfer, which also narrowed the rural intern income gap. Therefore, rural income distribution shows inverted U-shaped curve in a certain period of time during the whole rural population migration process.

2) Analysis on Myrdal's regional unbalanced development theory

The regional imbalance of rural economic development is also an important factor contributing to the widening income gap between rural residents. According to Myrdal's regional unbalanced development theory, there are developed areas and underdeveloped areas in a region. With natural condition and policy factors, the former gets developed first. Since the relatively higher income and perfect infrastructure of the former, the high-quality labor force and production factors of the latter transfers to the former constantly, which further widens the gap between the two. As a result, developed areas develop at an increasingly faster speed with constant capital inflow to gain higher profits, while underdeveloped areas fall into vicious spiral due to the loss of talent and resources. In comparison, farmers in developed areas have more employment opportunities and income approach, which widens rural income disparity of the two. When developed areas keep high-speed development for a period of time, the opportunity of high return on investment keeps decreasing because of rising wages and rent, the increasing production cost and low return rate on investment. What is more, due to factors like traffic jam, deteriorating environment and rising living cost loom large, human capital and funding of the developed areas begins to spread to the backward areas, while the relatively cheaper labor cost and raw materials of the latter contributes to its economic take-off and high-speed rural residents' income, which narrows the income gap between rural residents of the two areas. The policy "to allow people from certain regions to rich early, and the one who 
has been rich should help others” since China's reform and opening up has objectively led to the Kuznets curve phenomenon in rural economic development and income distribution.

\subsection{Analysis on the Current Situation of Rural Economic Development and Rural Residents' Income Distribution Gap}

This thesis intends to employ the most commonly used Gini coefficient to represent rural residents' income gap. Using Gini coefficient to reflect economic inequality of all residents is very mature and more direct in form, in addition, it can offer warning for the polarization between the rich and the poor. According to relevant research, there is high correlation between per capita net income of rural residents and the economic development level of rural areas. The thesis takes per capita net income of rural residents in a region to represent its economic development status.

1) National level

Income inequality of China's rural residents is getting increasingly serious in recent years, with the income inequality of rural residents far greater than that of urban ones. The data on per capita net income of rural residents in five equal income groups in 2014 China Statistical Yearbook shows that highest income group was 6.47 times that of the lowest income group in 2000, while that ration rose to 8.24 in 2013. In the meanwhile, according to 2012 China Household Survey Yearbook, in the year 2000, net income of rural residents in China was 2253.4 yuan, with the rural Gini coefficient be at 0.3536 . However, in the year 2011, the corresponding net income of rural residents in China was 6977.3 yuan and the rural Gini coefficient rose to 0.39, which demonstrates an obvious expanding income gap of rural residents.

2) Provincial and municipal level

Since bureau of statistics did not release the rural Gini coefficient of each province, this thesis employs POVCALNET, the World Bank online tools, to calculate rural Gini coefficient of 18 provinces from 1999 to 2013 based on the grouped data of rural residents' income in each province's statistical yearbook. The 18 provinces are Inner Mongolia, Chongqing, Shaanxi, Gansu, Qinghai and Xinjiang in west China, Shanxi, Henan, Anhui, Hubei, Jiangxi and Heilongjiang in central China, and Liaoning, Beijing, Hebei, Jiangsu, Shanghai and Fujian in east China respectively.

The thesis employs the rural per capita net income and the calculated yearly rural Gini coefficient of each province to test the possibility of the existence of rural Kuznets curve.

In Figure 1, the horizontal axis stands for rural residents per capita income, the vertical axis stands for rural

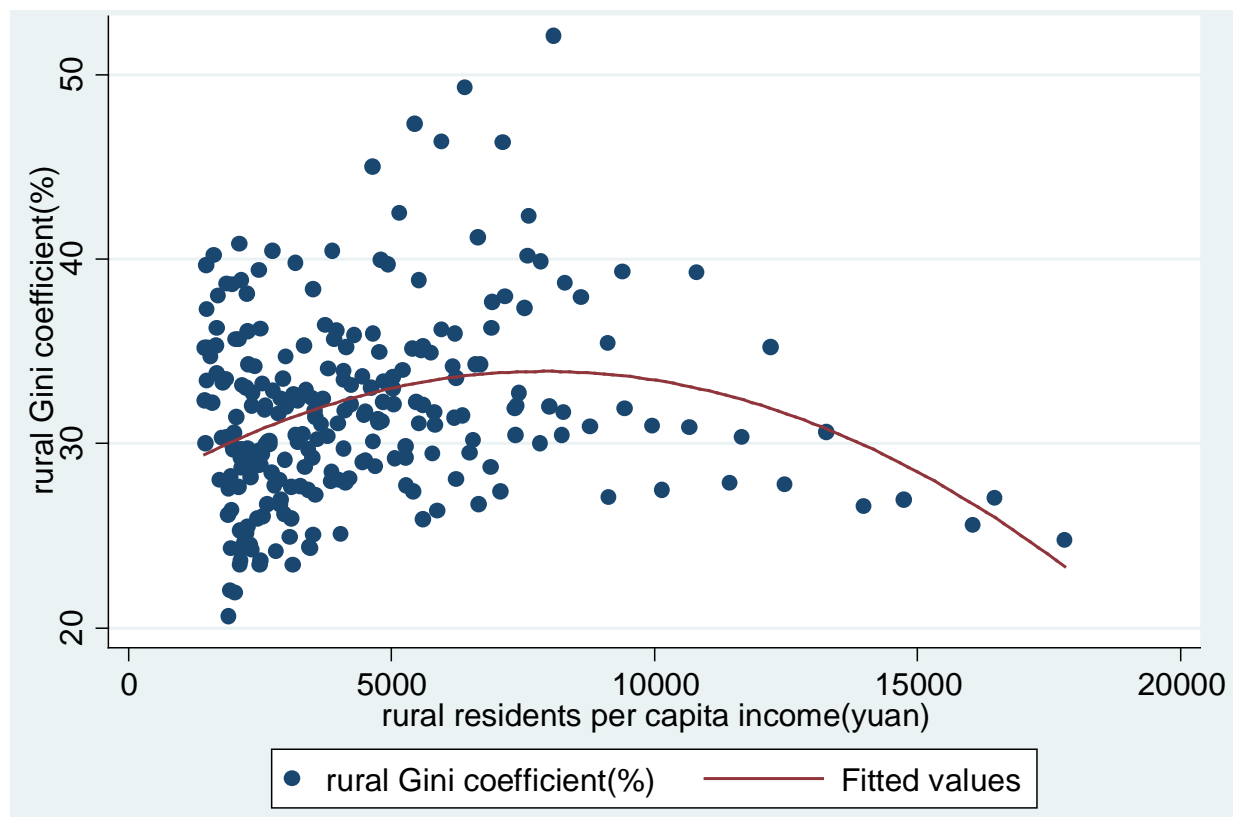

Figure 1. Relationship between Gini coefficient in China provinces and rural residents per capita income. 
Gini coefficient. By observing the scatter diagram of the 18 provinces' rural Gini coefficient and rural per capita income, we can clearly found that the two shows a positive correlation, which indicates that rural residents' inner income gap is widening while developing rural economy. In the meanwhile, the fitted quadratic curve in the statistical software Stata clearly shows an inverted U-shape, which enables us to infer the existence of rural Kuznets curve.

To further confirm the results, this thesis decides to use econometric model empirical analysis for further verification.

\section{Empirical Analysis}

\subsection{Model Specification}

1) In order to testify whether there is an inverted U-shaped relationship resembling that of Kuznets curve between China's rural economic development and rural residents' income gap, the thesis selects explanatory variables and control variables according to the relevant literature to define the following two measurement model groups [15] [16]:

$$
\begin{gathered}
\operatorname{GINI}_{i t}=\beta_{0}+\beta_{1} Y_{i t}+\beta_{2}\left(Y_{i t}\right)^{2}+\beta_{3} \text { Control }_{i t}+\varepsilon_{i t} \\
\operatorname{GINI}_{i t}=\beta_{0}+\beta_{1} \ln Y_{i t}+\beta_{2}\left(\ln Y_{i t}\right)^{2}+\beta_{3} \text { Control }_{i t}+\varepsilon_{i t} .
\end{gathered}
$$

Among which $\operatorname{GINI}_{i t}$ is explained variables represented by the rural Gini coefficient, while $Y_{i t}$ is explanatory variable represented by rural residents' net income that shows rural economic development status. $\ln \left(Y_{i t}\right)$ is to evaluate the logarithm of $Y_{i t}$. Control ${ }_{i t}$ represents other factors influence explained variable, including the proportion of urban population, the level of agricultural modernization [17]. $\varepsilon_{i t}$ is the random error. The subscripts $i$ and $t$ stand for the data of province $i$ in year $t$.

2) Control variables selection

The urban population proportion: It is generally assumed that the urbanization leads to agricultural population migrating to cities and work in the non-agriculture sectors, which will widen the income gap of rural internal. Nevertheless, the research of Zhou Yunbo (2009) argued that urbanization causes a shrinking ratio of low income peasant households since the new century, and will eventually lead to a slow speed in expanding rural residents' income gap [18].

The agricultural modernization level: Agricultural modernization helps to improve labor productivity in the agricultural sector, which narrows its income gap with the industrial sector, and eventually narrows the income gap between farmers engaged in agricultural production and non-agricultural activities. Agricultural mechanization is an important manifestation of agricultural modernization, the thesis takes the total power of agricultural machinery in cultivated area unit to measure agricultural modernization degree.

Highway density: A large number of documents show that the improvement of transportation facilities bring more employment opportunities and development opportunities for low-income residents.

Education investment: Relevant literature shows that public education plays an important role in narrowing income gap, because poor residents have less access to education with limited education resources. However, the popularization of educational opportunities and abundant education resources enhance the human capital of poor rural residents, which renders them stronger employment ability. The thesis takes junior high school students per capita public finance budget education as education investment.

Rural per capita public transfer payments: In general, income redistribution dominated by government can reduce the income gap between the residents. In recent years, with the comprehensive abolishing of agricultural taxes, the implementation of new rural medical cooperation and the construction of rural subsistence allowances and other policies as well, the proportion of transfer income in rural residents rose continuously. The public transfer payments, as the main source of rural metastatic income, is to lower poor and inequality, which is represented by rural per capita metastatic income in the thesis.

3) Data sources

The panel data of this thesis comes from the annual data of 18 China provinces from 1999 to 2013. Among which the rural per capita income, the proportion of urban population and rural residents per capita transfer income all comes from the provincial Statistical Yearbook. The junior high school students per capita public finance budget comes from China Educational Finance Statistical Yearbook. Highway density is calculated ac- 
cording to the provincial highway mileage divided by the corresponding land area, in which highway mileage comes from provincial Statistical Yearbook. Agriculture modernization degree is represented by agriculture acreage divided by total power of agricultural machinery, which comes from China Agricultural Machinery Industry Yearbook. Agriculture acreage derives from Statistical database of China Research Network.

\subsection{Regression Results of Panel Data Model}

The panel data model is divided into fixed effect model and random effect model. In order to ensure the robustness of the regression results, two methods are used to analyze the panel data (Table 1).

Regression results show that for model 1, regardless of the fixed effect model and random effect model, rural per capita net income of a coefficient is negative, the coefficient of the quadratic term is positive and is significant in the $1 \%$ significance level, which shows that China's rural economic development and rural residents income distribution has an inverted U-shaped relationship. In the process of rural economic development, the income gap between rural residents is increasing, while the pace of expansion is slowing down.

The semi-logarithmic regression model in Model 2 shows that $\ln Y_{i t}$ coefficient is positive and its square term is negative, which is significant in $1 \%$ significant level. The result again proves the existence of rural Kurtz curve. The results are still robust.

As for the regression results of control variables, the proportion of urban population in the regression results in most cases is neither significant nor robust. That may be due to our country's various urbanization level in different provinces and cities, which has a great influence on rural residents' income gap. The regression coefficient of education investment is negative, and is significant in most cases, which shows that education is conducive to the expansion of the income gap of rural residents. Agricultural modernization of regression coefficients are all positive but not significant. The rate in increasing agricultural productivity has a difficult in catching up with productivity of the secondary industry and the tertiary industry. That is why rural income gap continues to

Table 1. Panel data regression estimation results.

\begin{tabular}{|c|c|c|c|c|}
\hline Variation & $\begin{array}{c}\text { Model 1 } \\
\text { Fixed effect } \\
\text { regression }\end{array}$ & $\begin{array}{c}\text { Model 1 } \\
\text { Random effect } \\
\text { regression }\end{array}$ & $\begin{array}{c}\text { Model } 2 \\
\text { Fixed effect } \\
\text { regression }\end{array}$ & $\begin{array}{c}\text { Model } 2 \\
\text { Random effect } \\
\text { regression }\end{array}$ \\
\hline$Y_{i t}$ & $\begin{array}{l}0.00264^{* * * *} \\
\quad(4.97)\end{array}$ & $\begin{array}{l}0.00297^{* * *} \\
(5.73)\end{array}$ & & \\
\hline$\left(Y_{i t}\right)^{2}$ & $\begin{array}{c}-7.21 \mathrm{e}-08^{* * *} \\
(-2.91)\end{array}$ & $\begin{array}{c}-1.09 \mathrm{e}-07^{* * *} \\
(-4.4)\end{array}$ & & \\
\hline $\ln Y_{i t}$ & & & $\begin{array}{c}82.737^{* * * *} \\
(5.70)\end{array}$ & $\begin{array}{c}74.59029^{* * * *} \\
(4.87)\end{array}$ \\
\hline$\left(\ln Y_{i t}\right)^{2}$ & & & $\begin{array}{c}-5.511606^{* * * *} \\
(-5.90)\end{array}$ & $\begin{array}{c}-5.09109^{* * * *} \\
(-5.16)\end{array}$ \\
\hline Urbanization proportion & $\begin{array}{l}0.0764 \\
(0.95)\end{array}$ & $\begin{array}{c}-0.0343 \\
(-0.75)\end{array}$ & $\begin{array}{l}0.1706082^{* *} \\
(2.14)\end{array}$ & $\begin{array}{c}0.175084 \\
(0.33)\end{array}$ \\
\hline Education investment & $\begin{array}{c}-0.000539^{* *} \\
(-2.47)\end{array}$ & $\begin{array}{c}-0.000213 \\
(-0.97)\end{array}$ & $\begin{array}{c}-0.0006632^{* * *} \\
(-3.27)\end{array}$ & $\begin{array}{c}-0.0004811^{* * * *} \\
(-2.32)\end{array}$ \\
\hline Highway density & $\begin{array}{c}-0.0015 \\
(-1.28)\end{array}$ & $\begin{array}{c}-0.00295^{* * *} \\
(-2.78)\end{array}$ & $\begin{array}{c}-0.001922^{*} \\
(-1.70)\end{array}$ & $\begin{array}{c}-0.002412^{* * * *} \\
(-2.28)\end{array}$ \\
\hline Agriculture modernization & $\begin{array}{l}0.0779 \\
(0.05)\end{array}$ & $\begin{array}{l}0.0424 \\
(0.03)\end{array}$ & $\begin{array}{l}0.5620046 \\
(0.40)\end{array}$ & $\begin{array}{c}0.597587 \\
(0.46)\end{array}$ \\
\hline $\begin{array}{l}\text { Per capita public } \\
\text { transfer payments }\end{array}$ & $\begin{array}{c}-0.0064^{* * *} \\
(-2.42)\end{array}$ & $\begin{array}{c}-0.00762^{* * *} \\
(-2.46)\end{array}$ & $\begin{array}{c}-0.0024758^{* *} \\
(-2.04)\end{array}$ & $\begin{array}{c}-0.0034319^{* * * *} \\
(-2.71)\end{array}$ \\
\hline Constant & $\begin{array}{c}21.50^{* * *} \\
(8.34)\end{array}$ & $\begin{array}{l}25.97^{* * *} \\
(15.83)\end{array}$ & $\begin{array}{c}333.7352^{* * *} \\
(5.87)\end{array}$ & $\begin{array}{l}302.399^{* * *} \\
(5.02)\end{array}$ \\
\hline R square & 0.625 & 0.618 & 0.521 & 0.543 \\
\hline
\end{tabular}

Note: the figure in brackets are t-value, ${ }^{* * *},{ }^{* *}$ and ${ }^{*}$ stand for significance value below $1 \%, 5 \%, 10 \%$ respectively. 
widen in the process of agricultural modernization. Highway density coefficient is negative and rather significant, indicating the improvement of transportation infrastructure is in favor of the poor. The rural residents transfer payment plays a significant role in improving rural residents' income distribution status.

In conclusion, the results suggest that China's rural Kurtz curve does exist. In addition, combined with the scatter plot, we can infer that most provinces and cities are in the left side of the inverted -shaped curve, still far away from the inflection point.

\section{Conclusions and Policy Recommendations}

Firstly, the thesis discusses theoretical basis of Kurtz curves in rural China based on dual economy theory and regional unbalanced development theory. Then the thesis employs the panel data of 18 provinces from the perspective of empirical analysis to show that China's rural Kurtz curve does exist. To narrow the income gap of rural residents as soon as possible, the thesis offers some suggestions based on the results of empirical analysis:

1. Continuing to increase policy support to rural areas, promoting economic development in rural areas. Only the long-term and stable economic development in rural areas can solve the problem of rural poverty fundamentally, which can improve the income inequality among rural residents.

2. Improving the fiscal and taxation policies and social security system, strengthening transfer payments of rural poor residents; setting out reasonable tax policy and deepening tax system reform; giving full play to tax revenue in narrowing the gap between the rich and the poor; improving the level of social security in rural areas and expanding its coverage. As for persons living with disabilities and rural residents with low income, the government should strengthen the transfer payment s to improve people's livelihood.

3. Accelerating the pace of urbanization, and promoting the process of agricultural modernization; accelerating the transfer of rural surplus labor to promote the process of agricultural modernization; improving mechanization production and the degree of the scale and narrowing the gap between agricultural productivity and the productivity of secondary and tertiary industry to narrow the income gap between rural non-agriculture workers and rural agriculture workers.

4. Strengthening education investment and infrastructure improvement; strengthening education investment and infrastructure improvement and changing inequality of poverty groups in education, employment and available resources to eliminate the root causes of inequality fundamentally (Inequality in income distribution boils down to inequality in human capital and available resources).

\section{References}

[1] Kuznets, S. (1955) Economic Growth and Income Inequality. The American Economic Review, 45, 1-28.

[2] Robinson, S. (1976) A Note on the U Hypothesis Relating Income Inequality and Economic Development. American Economic Review, 66, 437-440.

[3] Chenery, H.B., Syrquin, M. and Elkington, H. (1975) Patterns of Development: 1950-1970. African Economic History, No. 2.

[4] Fields, G.S. (1980) Poverty, Inequality and Development. Cambridge University Press, Cambridge, United Kingdom.

[5] Fields, G.S. (1984) Employment, Income Distribution and Economic Growth in Seven Small Open Economies. Economic Journal, 94, 74-83. http://dx.doi.org/10.2307/2232216

[6] Deininger, K. and Squire, L. (1998) New Ways of Looking at Old Issues: Inequality and Growth. Journal of Development Economics, 57, 259-287. http://dx.doi.org/10.1016/S0304-3878(98)00099-6

[7] Chen, Z.S. (2002) Further Studies on Income Distribution Reform and Development. Economic Science Press, Beijing, China.

[8] Li, S. and Zhao, R.W. (1998) The Change of Income Distribution in China's Economic Reform. Management World, No. 1, 43-56.

[9] Li, S., Zhao, R.W. and Zhang, P. (1998) China’s Economic Transformation and Changes in Income Distribution. Economic Research, No. 4, 42-51.

[10] Guo, X.B. (2002) Kuznets Hypothesis Viewed from the Theory of Economics of Development: On the Causes for the Enlargement of Income Inequality in China. Management World, No. 3.

[11] Liu, R.T. and Ye, M.Q. (2006) Research on Kuznets Curve of China's Urban and Rural Income Disparity-An Empirical Analysis Based on Panel Data of Provinces (1978-2004). Inquiry into Economic Issues, No. 6, 9-13.

[12] Ma, X.P. and Gao, W. (2013) Research on the Relationship between Urban and Rural Income Gap and Economic 
Growth in China: An Empirical Analysis of the "Kuznets inverted U-Shaped Curve Hypothesis”. Price Theory and Practice, No. 1, 64-65.

[13] Lv, F. (2014) An Empirical Analysis of Kuznets’s Inverted U-shaped Curve in China. Public Finance Research, No. 5, $10-14$.

[14] Wang, X.L. and Fan, G. (2005) Analysis on the Trend of China’s Income Gap and Its Influencing Factors. Economic Research, No. 10, 24-36.

[15] Zhang, S.W., Lv, S.B. and Zhao, L. (2007) Kuznets's Inverted U-shaped Hypothesis: Based on the Analysis of the Gini Coefficient. Economic Review, No. 4, 40-45.

[16] Yu, K. (2011) Kuznets’s “Inverted U-shaped Curve” in Residents Income Distribution of China: an Empirical and Theoretical Analysis. Jianghuai Tribune, No. 4, 39-44.

[17] Gao, H.W. and Wang, S.L. (2009) Empirical Analysis on the Relationship between Economic Growth and Income Distribution. Contemporary Economic Research, No. 12, 46-49.

[18] Zhou, Y.B. (2010) When Will China's Income Gap Change Reach the Inflection Point of the Inverted U-shaped Curve. Economic Review, No. 4, 43-46. 